\title{
Letter to the Editor regarding Lipoedema - myths and facts, Part 1 and Part 5. European Best Practice of Lipoedema - Summary of the European Lipoedema Forum consensus. Phlebologie 2020; 49: 31-49
}

Lipedema is a disease of loose connective tissue (LCT)-not just fat. Constituents of LCT include cells and an extracellular matrix of collagen fibers around glycosaminoglycans (GAGs) bound to sodium and water.

A. Edema: The authors state "there is no evidence for the presence of edema in lipedema" [1]. Edema is defined as excess interstitial fluid (IF) [2] that is free, or bound in a GAG gel as in lipedema:

1. Overgrowth of blood vessels in lipedema tissue is not matched by increased lymphatic vessels [3], and capillaries are leaky [4] increasing IF.

2. The interstitium is enlarged in lipedema LCT $[3,5]$ with fibrosis and GAGs. $[6,7]$

3. Extracellular fluid is higher in the legs of women with lipedema, controlled for BMI $[8,9]$. In lipedema unlike lymphedema, GAG-bound IF doesn't flow to the hands and feet, sparing them.

4. GAGs bind sodium. Sodium content is higher in skin and LCT of women with lipedema [10].

5. Soft tissue inflammation increases interstitial sodium and GAG[11]. Inflammation $[3,5,12]$ and excess sodium are present in lipedema LCT [10].

6. Lipedema tissue is highly compliant [13]. As IF increases, pressure does not increase accordingly, and excess IF and stasis occur. Many women with lipedema have hypermobility, a connective tissue disorder affecting tissue compliance $[14,15]$.

7. Edemas with non-pitting edema have increased GAGs including localized myxedema, venous disease and lymphedema [16].

B. Manual therapy and compression: The authors state "treatment of lipedema with manual lymphatic drainage (MLD) therapy is obsolete" [1]. US therapists use deep tissue manipulation during MLD to improve lipedema tissue structure and drain excess fluid. MLD normalizes lipolytic responsiveness of femoral fat tissue [17], improves microcirculation and capillary fragility
[18], and reduces lipedema pain [19, 20]. Deep manipulation for lipedema [19] breaks down fibrotic fat, and reduces tissue volume, and fat by DEXA scan [21, 22]. We agree compression garments reduce inflammation; edema is part of inflammation.

C. Lipohypertrophy: The authors state, "lipohypertrophy is a painless disproportionate increase in adipose tissue" [1]. In a seminal paper, $40-50 \%$ of women with lipedema had pain or tenderness in the legs [23]. Thus pain is not an absolute requirement for a lipedema diagnosis. A woman with painful lipedema who underwent therapy and has no pain, still has lipedema. Further research is needed to discern if/how lipohypertrophy differs from lipedema.

D. Obesity, secondary lymphedema and bariatric surgery: The authors state "women with lipedema develop lymphedema secondary to obesity" [1]. A biomarker, PF4, shows lymphedema and lipedema are distinct from obesity [24]. Lymphangioscintigraphy of women with lipedema \pm obesity showed lymphatic system alterations [25], suggesting obesity is not a primary cause of lymphatic alterations or lymphedema in lipedema. Many severe obese women with lipedema do not develop lymphedema [26].

We recommend bariatric surgery for women with lipedema and obesity with metabolic complications [27-29]; longterm studies are needed to assess how lipedema progresses \pm obesity.

E. Psychology: We agree women with lipedema experience appearance-related distress. We also agree depression and poor mobility adversely affect quality of life [30] and increase pain. We have no evidence to support the statement that: "psychological factors can contribute significantly to the development of lipoedema" [31].

F. Liposuction: We disagree that "Liposuction is not a treatment option in patients with a $\mathrm{BMI}>35 \mathrm{~kg} / \mathrm{m}^{2}$ and central obesity
(WHtR > 0.5)" [1]. Women can develop lipedema LCT on the abdomen [14]. Lipedema patients should be considered individually for liposuction.

In conclusion, we discuss evidence edema in lipedema exists bound to GAGs sharing features with other edemas but with a different clinical presentation than lymphedema secondary to obesity, will benefit from manual therapy and liposuction, and merits research to understand its role in lipedema etiology. The authors state treatment of obesity and lymphedema are "by no means enough to treat the complex disease of lipoedema adequately. Our greatest desire is to make this absolutely clear!" [1]. We agree.

\section{Conflict of interest}

This paper was supported by NIH NHLBI grant 1 R13 HL147503-01, Standard of Care for Lipedema in the United States

Authors

Karen L. Herbst ${ }^{1,2}$, Linda Anne Kahn², ${ }^{2}$ Emily Iker, ${ }^{2,4}$, Rachelle Crescenzi ${ }^{5}$, Chuck Ehrlich ${ }^{2,6}$, Tami Faris ${ }^{2,7}$, Thomas Wright ${ }^{2,8}$, Lindy McHutchison ${ }^{2,9}$, Jaime Schwartz', 10, Erik Lontok2, 11, Michael S. Schwartz ${ }^{2,12}$, Molly Sleigh ${ }^{2,13}$, Steven M. Dean 2, 14, John R. Bartholomew2, 15, Polly Armour ${ }^{2,16}$, Margarita Correa-Perez ${ }^{2,17}$, Kathleen H. Lisson ${ }^{2,18}$, Ingrid A. Harten ${ }^{19}$, Nicholas Pennings ${ }^{2,20}$, Ethan Larson ${ }^{2,21}$, Andrea Brennan ${ }^{22}$, Joachim Zuther ${ }^{23}$

${ }^{1}$ Karen L. Herbst, MD, PC, Los Angeles, CA, USA

${ }^{2}$ The US Standard of Care Committee

${ }^{3}$ Lymphatic Therapy Services, San Diego, CA, USA

${ }^{4}$ Lymphedema Center, Santa Monica, CA, USA

${ }^{5}$ Vanderbilt University Medical Center, Nashville, TN, USA

${ }^{6}$ Lymph Notes, San Francisco, CA, USA

${ }^{7}$ Independent Contractor, Kansas City, KS, USA

8 Lipedema Surgical Solutions, O Fallon, MS, USA

${ }^{9}$ The Lipedema Center, Carolina Vein Center, Durham, NC, USA

${ }^{10}$ USC Keck School of Medicine, Los Angeles, CA, USA 
${ }^{11}$ Barth Syndrome Foundation, Larchmont, NY, USA

12 Pasadena Plastic Surgery, Pasadena, CA, USA

${ }^{13}$ Lighthouse Lymphedema Network, Atlanta, GA, USA

${ }^{14}$ The Ohio State University Wexner Medical Center, Columbus, $\mathrm{OH}$, USA

${ }^{15}$ Cleveland Clinic, Cleveland, $\mathrm{OH}$, USA

${ }^{16}$ Research Coordinator, Fat Disorders Resource Society, Illinois, USA

${ }^{17}$ Physical Medicine Institute, Orlando, FL, US

18 Solace Massage and Mindfulness, San Diego, California, USA

${ }^{19}$ Benaroya Research Institute at Virginia Mason, Seattle, WA, USA

${ }^{20}$ Campbell University School of Osteopathic Medicine, Buies Creek, NC, USA

${ }^{21}$ Larson Plastic Surgery, Tucson, AZ, USA

22 Brennan School-Casley-Smith USA, Scottsdale, AZ, USA

${ }^{23}$ Academy of Lymphatic Studies, Sebastian, FL USA

\section{Correspondence}

Karen Herbst, MD, PC, Los Angeles, CA, USA

The US Standard of Care Committee kaherbst@gmail.com

\section{References}

[1] Bertsch T, Erbacher G, Corda D et al. Lipoedema - myths and facts, Part 5. European Best Practice of Lipoedema - Summary of the European Lipoedema Forum consensus. Phlebologie 2020; 49: 31-49

[2] Mortimer PS, Levick JR. Chronic peripheral oedema: the critical role of the lymphatic system. Clin Med (Lond) 2004; 4: 448-453

[3] AL-Ghadban S, Cromer W, Allen M et al. Dilated Blood and Lymphatic Microvessels, Angiogenesis, Increased Macrophages, and Adipocyte Hypertrophy in Lipedema Thigh Skin and Fat Tissue. J Obes 2019; 2019: 8747461. doi:10.1155/2019/8747461. eCollection 2019. PMID: 30949365

[4] Curri SB, Merlen JF. Troubles Microvasculaires de Tissu Adipeux. Journal des Maladies Vasculaires (Paris) 1986; 11: 303-309

[5] Suga H, Araki ], Aoi N et al. Adipose tissue remodeling in lipedema: adipocyte death and concurrent regeneration. J Cutan Pathol 2009; 3: 3
[6] Felmerer G, Stylianaki A, Hägerling R et al. Adipose Tissue Hypertrophy, An Aberrant Biochemical Profile and Distinct Gene Expression in Lipedema. J Surg Res 2020; 253: 294-303

[7] Herbst KL. Lipedema is not just fat. https:// www.lipedema.com/lipedema-is-not-justfat2020

[8] Crescenzi R, Donahue PMC, Weakley S et al. Lipedema and Dercum's Disease: A New Application of Bioimpedance. Lymphat Res Biol 2019; 17: 671-679

[9] Ward L, Winall A, Isenring E et al. Assessment of bilateral limb lymphedema by bioelectrical impedance spectroscopy. Int J Gynecol Cancer 2011; 21: 409-418

[10] Crescenzi R, Marton A, Donahue PMC et al. Tissue Sodium Content is Elevated in the Skin and Subcutaneous Adipose Tissue in Women with Lipedema. Obesity (Silver Spring) 2018; 26: 310-317

[11] Reed RK, Rubin K. Transcapillary exchange: role and importance of the interstitial fluid pressure and the extracellular matrix. Cardiovasc Res 2010; 87: 211-217

[12] Foldi E, Foldi M. Lipedema. In: Foldi M, Foldi E, Hrsg. Foldi's Textbook of Lymphology. 551 Munich, Germany: Elsevier GmbH; 2006

[13] Harwood CA, Bull RH, Evans J et al. Lymphatic and venous function in lipoedema. $\mathrm{Br}$ J Dermatol 1996; 134: 1-6

[14] Herbst K, Mirkovskaya L, Bharhagava A et al. Lipedema Fat and Signs and Symptoms of Illness, Increase with Advancing Stage. Archives of Medicine 2015; 7: 1-8

[15] Beltran K, Herbst KL. Differentiating lipedema and Dercum's disease. Int J Obes (Lond) 2017; 41: 240-245

[16] Roberts MA, Mendez U, Gilbert RJ et al. Increased Hyaluronan Expression at Distinct Time Points in Acute Lymphedema. Lymphatic Research and Biology 2012; 10: 122128

[17] Varaliová Z, Vlasák R, Čížková T et al. Lymphatic drainage affects lipolytic activity of femoral adipose tissue in women. Int J Obes 2020; 5: 020-0559

[18] Szolnoky G, Nagy N, Kovacs RK et al. Complex decongestive physiotherapy decreases capillary fragility in lipedema. Lymphology 2008; 41: 161-166

[19] Casley-Smith JR, Casley-Smith JR. Modern Treatment for Lymphoedema. Fifth, revised Edition South Australia: The Lymphoedema Association of Australia, Inc; 1997

[20] Szolnoky G, Varga E, Varga M et al. Lymphedema treatment decreases pain intensity in lipedema. Lymphology 2011; 44: 178-182
[21] Herbst KL, Ussery C, Eekema A. Pilot study: whole body manual subcutaneous adipose tissue (SAT) therapy improved pain and SAT structure in women with lipedema. Horm Mol Biol Clin Investig 2017; 33

[22] Ibarra M, Eekema A, Ussery C et al. Subcutaneous adipose tissue therapy reduces fat by dual X-ray absorptiometry scan and improves tissue structure by ultrasound in women with lipoedema and Dercum disease. Clin Obes 2018; 8: 398-406

[23] Wold LE, Hines EA Jr, Allen EV. Lipedema of the legs; a syndrome characterized by fat legs and edema. Ann Intern Med 1951; 34: 1243-1250

[24] Ma W, Gil H], Escobedo N et al. Platelet factor 4 is a biomarker for lymphatic-promoted disorders. JCI Insight 2020; 11: 135109

[25] Forner-Cordero I, Olivan-Sasot P, RuizLlorca $C$ et al. Lymphoscintigraphic findings in patients with lipedema. Rev Esp Med Nucl Imagen Mol 2018; 37: 341-348

[26] Witte MH, Witte CL. Massive obesity simulating lymphedema. New England Journal of Medicine 1992; 327: 1927

[27] Bast JH, Ahmed L, Engdahl R. Lipedema in patients after bariatric surgery. Surg Obes Relat Dis 2016; 12: 1131-1132

[28] Pouwels S, Huisman S, Smelt HJM et al. Lipoedema in patients after bariatric surgery: report of two cases and review of literature. Clin Obes 2018; 8: 147-150

[29] Pouwels S, Smelt HJ, Said M et al. Mobility Problems and Weight Regain by Misdiagnosed Lipoedema After Bariatric Surgery: Illustrating the Medical and Legal Aspects. Cureus 2019; 11: e5388

[30] Dudek JE, Bialaszek W, Ostaszewski P et al. Depression and appearance-related distress in functioning with lipedema. Psychol Health Med 2018; 3: 1-8

[31] Bertsch T, Erbacher G. Lipoedema - myths and facts Part 1. Phlebologie 2018; 47: 84-92

\section{Publication note}

Letters to the editor do not necessarily represent the opinion of the editor or publisher. The editor and publisher reserve the right to not publish letters to the editor, or to publish them abbreviated or in extracts.

\section{Bibliography}

Phlebologie 2021; 50: 5-6

Published online: October 1, 2020

DOI 10.1055/a-1217-0961

ISSN 0939-978X

(C) 2020. Thieme. All rights reserved.

Georg Thieme Verlag KG, Rüdigerstraße 14,

70469 Stuttgart, Germany 